\title{
Competency-based Medical Education, Entrustment and Assessment
}

\author{
*Jyoti Nath Modi, \#Piyush Gupta And Tejinder Singh \\ From the Departments of *Obstetrics and Gynecology, People's College of Medical Sciences and Research Center, Bhopal; \\ ${ }^{\#}$ Pediatrics, University College of Medical Sciences, New Delhi; and CMCL-FAIMER Regional Institute, CMC, Ludhiana; India. \\ Correspondence to: Dr Tejinder Singh, Program Director, CMCL-FAIMER Regional Institute, Christian Medical College, \\ Ludhiana, Punjab 141 008, India.cmcl.faimer@gmail.com
}

The realization that medical graduates are failing to serve the health needs of the society has compelled the medical educationists and regulatory authorities worldwide to review the medical training. A medical curriculum oriented towards developing the key competencies that enable a fresh graduate to be delivering socially responsive health care is seen as a promising step towards alleviating this problem. This calls for a departure from the traditional approach of organizing the curricular components around educational objectives, to a competency-based approach for planning the curriculum. The present article discusses the concept of competency-based medical education in Indian context, the steps in planning and implementing such a curriculum, and the key aspects of assessment for its effective implementation.

Keywords: Competency, Competency-based medical education, Assessment, Outcome-based education, Competency framework.

$\mathrm{M}$ edical schools came into being with the purpose of generating a scientifically trained professional workforce for serving the health needs of the society. Over the years, a perceptibly increasing gap between the health professionals' education, health care delivered, and societal health needs has raised global concerns $[1,2]$. Medical schools are increasingly facing the question, 'Are they producing graduates who are competent to cater to health needs of the society?' - Perhaps, not in entirety. For any corrective action; therefore, it is only befitting that we re-trace and work our way backwards from first defining the expected roles of a physician that best serve the healthcare requirements of the community (local and global) and also to clearly state the characteristics and abilities of doctors graduating from medical schools that enable them to perform these roles well [3]. The curricula then need to be designed towards achieving these outcome requirements steered by appropriate assessment methods. Herein lies the origin and essence of Competency-based Medical Education (CBME).

The goal of Undergraduate (UG) medical training is to produce 'doctors of first contact' or 'primary care physicians'. Having stated this goal, most traditional curricula and training programs, including those in Indian institutions, have been designed around the educational/ learning objectives [2]. These objectives largely allude to knowledge base with some reference to procedural skills, and behavior to be developed during the course of training. The holistic description of the outcome product of a medical school viz, the array of abilities of a fresh graduate, so as to perform the expected roles in providing health care to the community` has been lacking. Accordingly, assessment methods also were traditionally designed to measure attainment of knowledge or specific skills rather than the ability of the graduate in delivering judicious and contextual health care in authentic settings.

Awakened to this misalignment of training and needs, the efforts at making the 'competencies' as the chief driving force of medical training and curricular planning has gained momentum since the turn of the century $[1,2,4]$. In this article we discuss the concept of competency-based medical education in comparison to the traditional curricula in the Indian perspective, and also its implementation, particularly the assessment for such a medical training.

\section{DeFinitions}

The dictionary meaning of the terms 'competency' or 'competence' is "ability to do something" or "ability for a task". While the two terms are used interchangeably, competencies may also be viewed as ingredients of competence i.e., many specific competencies in combination constitute a broader area of competence [5]. Competence in a particular area encompasses many aspects and hence is best expressed as a description (statement) of abilities in context of setting, experience and time (or stage of training) [5-7].

A comprehensive and widely cited definition of Professional competence as proposed by Epstein and 
Hundert in 2002, states: "the habitual and judicious use of communication, knowledge, technical skills, clinical reasoning, emotions, values, and reflection in daily practice for the benefit of the individual and community being served" [4].

With evolving understanding and increasing consensus on the issue, a definition of Competency-based Education as proposed by Frank, et. al. in 2010, makes the core purpose and curricular elements of CBME more lucid: "Competency-based education (CBE) is an approach to preparing physicians for practice that is fundamentally oriented to graduate outcome abilities and organized around competencies derived from an analysis of societal and patient needs. It de-emphasizes timebased training and promises greater accountability, flexibility, and learner-centeredness" [8]. Some experts consider CBME as another form of outcome-based education (OBE), where learning outcomes assume more importance than learning pathways or processes.

\section{Global Movement Towards Competency-Based Medical Education}

Competencies are context-dependent and hence are contextually expressed and communicated. This has resulted in various competency frameworks in use in different countries/regions. Also, within the same country, these frameworks have undergone modifications and refinements over time.

In United States, the Outcome Project was initiated by the Accreditation Council for Graduate Medical Education (ACGME) in 2001 for emphasizing the 'educational outcomes' in terms of competencies to be achieved during the course of training $[9,10]$. These competencies were identified under six domains, also referred to as general competencies, for all physicians irrespective of specialty. These are: Medical Knowledge, Patient care, Interpersonal and Communication skills, Professionalism, Practice-based learning and improvement, and System-based practice. They provided a framework for education and evaluation by specifying the end product rather than the desired training process or pathway. As a refinement measure towards assessment and defining the training pathway the ACGME launched the 'Milestones Project' in 2007 [7,11]. Thus subcompetencies, that serve as 'milestones' along the way to becoming fully competent, and hence must be achieved during the course of training were specified for each outcome competency [9].

In United Kingdom, the General Medical Council defined the outcomes and standards of graduate medical education, and brought out the details of competency framework in form of the document 'Tomorrow's Doctors' in 1993, that underwent further refinements over time [12]. Three broad outcomes were specified for medical graduates: (i) Doctor as a scholar and a scientist, (ii) Doctor as a practitioner, and (iii) Doctor as a researcher. Under each of these heads, sub competencies were further specified. The standards of teaching learning and assessment were further grouped under nine domains. For each domain, the standards, the criteria and the evidence (for evaluation) were specified in concrete terms [12].

The Royal College of Physicians and Surgeons of Canada (RCPSC) expressed the outcome of undergraduate medical training in terms of seven 'roles' of a physician and developed competency framework based on these - the Canadian Medical Education Directions for Specialists (CanMEDS) [13]. These roles were: medical expert, communicator, collaborator, manager, health advocate, scholar and professional.

The National Undergraduate Framework in Netherlands is yet another example of a well implemented outcome competency-based medical education framework [3]. Medical educationists from the Netherlands further propose that competencies are perhaps better observed and measured as Entrustable Professional activities (EPA), discussed later in the article [14]. An effort at defining outcomes has also been noted from Vietnam, Mexico and China [15].

\section{Comparison With Traditional Curriculum}

A comparative analysis of traditional discipline-based curriculum and competency-based curriculum is provided in Web Table I [2,3,5,14,16-18]. However, this analysis should not lead us to believe that one approach should completely replace the other. Incorporating elements of competency-based training utilizing the systems approach, and retaining the strengths of the traditional curricula would be desirable. This would certainly be a challenging task.

The three key steps in planning a competency-based curriculum, as suggested by experts and utilized by institutions running such programs $[5,19-22]$ are:

1. Identification of competencies

2. Content identification and program organization

3. Assessment planning and program evaluation

For implementation, they can be further divided into component steps and strategies as shown in Table I. Additionally, faculty development and creating conducive environment is a must for effective delivery of the curriculum. 
For program organization and assessment planning, it is important to remember that the competencies are developmental, i.e., expertise in a said area progressively changes over time and with experience. This has two implications: first, attainment of a competency can be viewed as passing through intermediate levels of expertise in various aspects of that competency, to be achieved (corresponding to the stage of learning) during the course of becoming fully competent - akin to the rungs of a ladder. Dreyfus and Dreyfus proposed a model of phase-wise learning with developmental stages of skill acquisition, the stages being Novice, Advanced beginner, Competence, Proficiency and Expertise [23,24]. This model can also be applied to medical education as illustrated in Table II. These meaningful achievement points that mark the attainment of a predefined performance level during the learning phase have been given different labels, e.g., the Accreditation Council for Graduate Medical Education (ACGME), USA, refers to these as 'Milestones' to be achieved on way towards becoming fully competent $[7,25]$.

The second consequence is, that a level of expertise for being called 'fully competent' needs to be specified. This cut-off is not set at the minimum level of expertise but at a level when the person can act independently and take responsibility for his action or performance in that area. Therefore, it is rightly said that the ultimate goal in

TABLE I STEPS OF COMPETENCY-BASED CURRICULUM PLANNING AND STRATEGIES FOR IMPLEMENTATION

\section{Steps for planning Competency-based Curriculum Steps and strategies for implementation}

I Identification of competencies

II Content identification \& Program organization

III Assessment planning and Program evaluation
- Competency identification by consensus opinion of experts, health needs, analysis of physician activities, self-report by physicians to identify critical elements of behavior, critical incidents, public health statistics, medical records, practice setting and resources.

- Exactly define required competencies and their components: Bring out statement of learning outcomes and communicate to faculty and students

- Identify corresponding course content

- Course organization: sequencing, learning opportunities, select educational activities, experiences and instructional methods

- Time organization: delineate minimum and maximum time period of training; Create space for feedback sessions and opportunity to reflect.

- Define the desired level of mastery/expertise in each area

- Define milestones or achievement points along development path for competency i.e. charting of student progression pathway.

- Identify observable and measurable form of competencies in real settings; e.g. EPA

- Define performance criteria: Establish minimum acceptable norms of summative performance and intervening levels of expertise.

- Select assessment tools to measure progress along the charted pathways i.e. formative assessment for achievement of milestones

- Develop a longitudinal assessment program (rather than standalone formative and summative assessments), with emphasis on WPBA methods: Make a blueprint with areas to be assessed, timing and assessors

- Design an outcomes evaluation program with scope for curricular review and improvement

- Faculty development and student orientation

- Ensuring conducive educational environment

- Student selection: incorporate some mechanism for assessing aptitude and motivation towards pursuing medical studies and delivering health care 
TABLE II APPLICATION OF Dreyfus Model to CURRICUlAR FrameWORKS OF COMPETENCY-BASEd MEdiCAL EdUCATION

\begin{tabular}{|c|c|c|c|}
\hline Dreyfus model & \multicolumn{2}{|c|}{ Assessment of 'Competency' in CBME } & $\begin{array}{l}\text { Assessment of an 'Entrustable professional } \\
\text { Activity'(EPA) }\end{array}$ \\
\hline \multirow{2}{*}{$\begin{array}{l}\text { Developmental } \\
\text { steps of skill } \\
\text { acquisition as } \\
\text { studied in } \\
\text { various learning } \\
\text { situations }\end{array}$} & \multicolumn{2}{|c|}{$\begin{array}{l}\text { Stepwise achievement of 'Milestones' towards } \\
\text { acquisition of a Competency }\end{array}$} & $\begin{array}{l}\text { Stepwise acquisition and integration of } \\
\text { several competencies towards achieving }\end{array}$ \\
\hline & $\begin{array}{l}\text { Example1: Communication with } \\
\text { patients } \\
\text { (UG to PG years) }\end{array}$ & $\begin{array}{l}\text { Example 2: Performance } \\
\text { of Caesarian section } \\
\text { (PG training in OBG) }\end{array}$ & $\begin{array}{l}\text { Example: ‘Care of the Neonate’ as an } \\
\text { EPA for PG training in Pediatrics } \\
\text { (This EPA requires an integration of } \\
\text { competency in patient care, procedural } \\
\text { skills, communication \& counseling skills, } \\
\text { teamwork, managerial \& leadership skills) }\end{array}$ \\
\hline Novice & $\begin{array}{l}\text { Able to talk with the patient so as to } \\
\text { take basic medical history according } \\
\text { to established framework. } \\
\text { (At entry: II-III Semester MBBS } \\
\text { student) }\end{array}$ & $\begin{array}{l}\text { Observes: } \\
\text { As second assistant during } \\
\text { surgery }\end{array}$ & $\begin{array}{l}\text { Level 1:Can be entrusted with examination } \\
\text { of newborn to look for congenital } \\
\text { anomalies }\end{array}$ \\
\hline $\begin{array}{l}\text { Advanced } \\
\text { beginner }\end{array}$ & $\begin{array}{l}\text { Able to establish rapport with the } \\
\text { patient and take a medical history } \\
\text { for a diagnostic workup. Able to } \\
\text { counsel the patient for health } \\
\text { practices such as diet, hygiene. } \\
\text { (Mid level: IV - VII Sem MBBS) }\end{array}$ & $\begin{array}{l}\text { Assists: } \\
\text { As first assistant to a senior } \\
\text { during surgery }\end{array}$ & $\begin{array}{l}\text { Level 2: } \\
\text { Can be entrusted to attend deliveries, } \\
\text { receive and resuscitate term newborns in } \\
\text { uncomplicated cases. }\end{array}$ \\
\hline Competence & $\begin{array}{l}\text { In addition to above: able to take a } \\
\text { history of delicate personal issues } \\
\text { and make a provisional diagnosis } \\
\text { based on history. } \\
\text { Able to counsel for taking informed } \\
\text { consent for surgeries and procedures } \\
\text { (UG Exit level: VIII-IX Sem \& } \\
\text { Internship) }\end{array}$ & $\begin{array}{l}\text { Directly supervised: } \\
\text { Operates under supervision } \\
\text { of a senior who scrubs and } \\
\text { assists during the surgery. }\end{array}$ & $\begin{array}{l}\text { Level 3: } \\
\text { Can be entrusted with immunization and } \\
\text { management of common problems in } \\
\text { newborns in outpatient setting. }\end{array}$ \\
\hline Proficiency & $\begin{array}{l}\text { In addition to above: } \\
\text { Able to counsel patient and care givers } \\
\text { for a newly made diagnosis, diagnosis } \\
\text { of serious illness and for seriously ill } \\
\text { patients. } \\
\text { (I-II Year PG students) }\end{array}$ & $\begin{array}{l}\text { Indirectly supervised: } \\
\text { The expert is available and } \\
\text { supervises without actually } \\
\text { scrubbing for surgery. }\end{array}$ & $\begin{array}{l}\text { Level 4: } \\
\text { Can be entrusted with receiving and } \\
\text { resuscitation of the newborn in } \\
\text { complicated cases such as preterm, } \\
\text { growth restriction, large baby. }\end{array}$ \\
\hline Expertise & $\begin{array}{l}\text { In addition to above: } \\
\text { Able to counsel Patient's care givers } \\
\text { in the event of death of patient. } \\
\text { (III Year PG student) }\end{array}$ & $\begin{array}{l}\text { Independent: } \\
\text { Without senior supervision }\end{array}$ & $\begin{array}{l}\text { Level 5: } \\
\text { Can be entrusted with management of } \\
\text { common problems in the newborns in } \\
\text { intensive care setting }\end{array}$ \\
\hline
\end{tabular}

CBME is not merely attainment of competency but an expertise (specified) in the area [16]. These two aspects are an important consideration in designing the formative and summative assessment in competency-based education.

\section{Assessment In CBME}

Some pertinent issues with regards to assessment in
CBME are discussed below:

\section{What to assess?}

In CBME, the outcome is expressed in terms of competencies. Medical education literature distinguishes between the terms 'competence' (meaning 'able to do') and 'performance' (meaning 'actually does'). According to Miller's pyramid model of clinical competence, the 
assessment of performance is at the highest level i.e. the 'Does'; and competence assessment is a level below i.e 'Shows how'. Naturally, performance assessment provides a more authentic picture of trainees' functionality in real clinical settings [17]. While competence can be assessed in examination setting using simulations and with tools such as Objective Structured Clinical Examination (OSCE), it can perhaps be better inferred from observable workplace performance using Workplace-based Assessment (WPBA) tools [18] .

\section{What to Measure While Assessing?}

Assessment requires identification of measurable and observable entities. This could be in the form of whole tasks that contribute to one or more competencies or assessment of a competency per se. While it appears reasonably justifiable to work on this framework, there have been concerns that attaining individual competencies may not actually lead to actual or acceptable performance. A trainee who is competent in history taking, physical examination and treatment planning, may still be unable to actually treat a patient. In this context, the concept of 'Entrustable Professional Activity' (EPA) [6] makes a lot of sense.

The EPA encompasses a set of professional work activities that together constitute the particular profession or specialization. Only after mastering a certain set of competencies can a trainee be entrusted with carrying out a particular professional activity with responsibility $[14,26]$. Observing and measuring competencies in form of EPA gives a more authentic information about the ability of the trainee to function as a professional in real life situation, and hence a better validity to assessment.

Let us try to illustrate this concept by using a simple example. While teaching driving to a novice, we set certain objectives for ourselves. For example, he 'should be able to start the engine', 'change the gears', and 'coordinate the release of clutch and accelerator' and so on. Attainment of these does not mean that he will be able to drive a car. However, if we change our outcome to 'competent to drive a car' then this problem can be avoided and we will continue our training till the trainee is able to drive a car. When the trainee demonstrates his ability to drive a car, we can call him competent. However, there may be more issues to it. He may be able to drive a small car but not a large one or he may be able to drive a car in a small town but not in the traffic of a metropolis or not in a hilly terrain. We may entrust a trainee driver to drive us in a small town with not much of traffic but need to provide more training before we can entrust him to drive us in a metro. On the same analogy, we have different levels of trust on the trainees depending upon their degree of expertise, stage of training and context of performance. The concept of EPA will be further discussed in detail in our next article in this series.

In our day-to-day practice, we all entrust night on- call residents with different levels of tasks - we depend on someone to be able to decide on what samples to collect but may not depend on him/her to make the choice of an antibiotic. EPAs help us to decide the level of trust we can place on a trainee to independently handle a given task.

It is also easier to observe and judge the proficiency with which a certain job activity is performed rather than trying to observe and measure each competency contributing to it. The term 'entrustable' in EPA inherently conveys the minimum acceptable standard i.e., the trainee is able to carry out the said clinical activity independently, can take responsibility for the same and hence can be entrusted with it. Ten Cate proposed that once the EPA is of an acceptable standard, a written statement to this effect may be issued to the trainee: a Statement of awarded responsibility (STAR) [14]. Assessment of EPA may have a relatively more meaningful and utilitarian interpretation, especially in formative assessments.

Also, it is of extreme importance to define standards of measurement of sub-competencies (e.g., Milestones or benchmarks; Levels of EPA) to be achieved at various stages of training. This charts out the desired pathway to becoming fully competent. Examples of developmental phases of attainment of competency and entrustment of professional activity, based on Dreyfus model are shown in Table II. Though the framework of EPA appears more suitable for Postgraduate training, it may also by utilized for Undergraduate medical training thus providing a developmental continuum to specialist training [27] The next paper in this series of medical education articles is dedicated to a full discussion on EPA.

\section{How to Measure: the Methods, Tools and Reporting}

Since CBME focuses on the outcome, it is important to observe and assess (and learn) at workplace. Daily practice area provides a richer source of information rather than isolated hand-picked tasks in examination setting. The WPBA methods assess at the 'does' level of Miller's pyramid and hence are most suitable [18]. These include mini-Clinical Evaluation Exercise (mini-CEX), Directly Observed Procedural Skills (DOPS), mini-Peer Assessment Tool (mini-PAT), Multisource feedback (MSF) as some of the common ones. Each of the tools can provide information about more than one competency; and any competency can be assessed in a better way by using more than one tool (triangulation). We have already discussed WPBA in detail in an earlier paper [27]. 
Another aspect is the recording and reporting of observations. There has been an undue emphasis on objectification of assessment scores [16]. Subjective interpretations of assessment have been underutilized and in fact been maligned to some extent. To some extent, it has been so because subjectivity has been misinterpreted as bias. This concern can be minimized by utilising multiple assessors over multiple occasions and settings. Judgment by an expert can be well expressed subjectively in words. It may in fact be more meaningful and useful to the trainee than a set of scores or categories conveyed at the end of assessment. This is particularly true for CBME since competencies are developmental and their progression depends heavily on the appropriate steering by assessment. The formative function of assessment is served well by subjective reporting of assessment.

Recently, there is increasing emphasis on utilising qualitative approach in assessment [16]. Use of student narratives and portfolios can be a rich source of information about student learning. Tekian, et al. [28] propose redefining of 'competence' itself in terms of construct narratives rather than as a checklist of component tasks.

Feedback: Whatever the assessment method, tool or reporting format, it is of utmost importance to provide an early and effective feedback to the trainee, preferably based on direct observation. Development of competencies hinges on the feedback received by the student trainee so that student progresses through the charted milestones. There is evidence in literature that establishes feedback as the most important determinant of learner progression [16].

\section{When to Assess?}

Frequent (or continuous) formative assessments that allow for and promote developmental progression are desirable in CBME. This helps to keep the trainee on the correct trajectory towards end outcomes [18]. Hence there is a greater emphasis on formative assessment in CBME.

\section{Who Should Assess?}

Faculty, peers, colleagues may assess depending on the competency being assessed. It is more important that the assessors are trained in using the method and tools that they use. Inter-rater variation in assessment can be reduced by assessor training as well as defining the standards for expected outcomes.

\section{Standards of Assessment in CBME}

It is well expressed by educationists that expertise and not competence is the ultimate goal in CBME [16]. The standards of acceptable level of expertise must be welldefined in competency-based training programs, and these must be defined not just for the outcomecompetencies but also for the intervening milestones to be achieved by the trainee. While establishing cut off standards, it is important to adopt a criterion-based approach $[16,17]$. That is, the set standard is an absolute level of performance (or competence) and is not dependent on the performance of other students. Adopting a normative-approach has the inherent risk that the standards may be set below acceptable level of expertise.

\section{CBME: THE INDIAN SCENARIO}

In India, there has been a relatively recent need-driven movement towards competency based medical education, and it is yet in a fledgling stage of discussions and planning. The Graduate Medical Education Regulations 1997 (GMER) of the Medical Council of India (MCI) mention the term 'competent' under institutional goals but do not define it further [29]. Following a series of meetings and deliberations, reforms were suggested in the form of 'Vision 2015' document in 2011 [30]. For the first time, the outcomes of graduate medical education were expressed as the competencies that an 'Indian Medical Graduate' would develop so as to function as a 'Basic Doctor' or physician of first contact to the people of India and the world. The five roles of a Basic doctor were stated as: Clinician, Leader and team member, Communicator, Lifelong learner, and Professional (who is ethical, responsive and accountable to patients, community and profession). The competencies to be developed to perform the above roles were also specified. The term competency was meant to imply 'desired and observable ability in the real life situation'. Unfortunately, in these deliberations, assessment was neither discussed in appropriate details nor was an assessment program aligned to outcomemeasurement included. The document did mention in passing that assessment be 'criterion referenced' without giving any further details.

Based on above deliberations and documents, the new Graduate Medical Education Regulations 2012 (GMER 2012) were proposed [31]. A salient feature of this revision of medical curriculum was emphasis on competency-based curriculum. While subject-wise specific outcome competencies were mentioned in this document, the alignment of assessment towards measuring competencies again remained largely unaddressed. The Postgraduate Medical Education Regulations 2000 (PGMER) of the MCI merely mention that the PG curriculum be competency-based, and that 
each department must produce statement of competencies [32].

Hence, we as a country still have a long road ahead towards implementing competency-based medical training. There is a need to review and revise our curriculum respecting the key role of assessment in achieving the deliverables. With the benefit of the existent curricular frameworks in use in different nations, we need to develop a competency framework suited to our needs and feasible in our settings and resources.

\section{Faculty Development}

Since the competency-based training program and assessment methods differ in many ways from the traditional curricula, it is important not only to orient the faculty to it but also to train the faculty in using the appropriate assessment methods. Of particular importance is the faculty training for improving the direct observation skills and feedback skills.

\section{Where We STAND AND What NeEdS to BE Done}

As we move towards developing a competency-based approach to medical education in our country, it is crucial to sensitize and prepare the faculty for the change. An initial combined and organized effort for identification of general competencies and specialty competencies may be a good starting point. Assessment has a key role in shaping the outcomes and success of a curriculum and hence must be carefully planned.

Contributors: TS: conceptualized the paper; JNM wrote the first draft; PG provided critical comments. All authors approved the final draft.

Funding: None; Competing interests: None stated.

\section{REFERENCES}

1. Long DM. Competency-based residency training: The next advance in Graduate Medical Education. Acad Med. 2000;75:1178-83.

2. Frenk J, Chen L, Bhutta ZA, Cohen J, Crisp N, Evans T, et al. Health professionals for a new century: transforming education to strengthen health systems in an interdependent world. Rev Peru Med Exp Salud Publica. 2011;28:337-41.

3. Harris P, Snell L, Talbot M, Harden RM for the International CBME Collaborators. Competency-based medical education: implications for undergraduate programs. Med Teach. 2010;32:646-50.

4. Epstein RM, Hundert EM. Defining and assessing professional competence. JAMA. 2002;287:226-35.

5. Frank JR, Snell LS, Cate OT, Holmboe ES, Carraccio C, Swing SR, et al. Competency-based medical education: theory to practice. Med Teach. 2010;32:638-45.

6. Englander R. Glossary of Competency-based Education

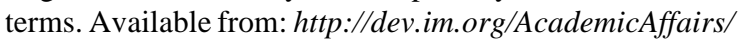
milestones/Documents/CBME\%20Glossary.pdf. Accessed
November 15, 2014.

7. Orgill BD, Simpson D. Towards a glossary of competencybased medical education terms. J Grad Med Educ. 2014;6:203-6.

8. Frank JR, Mungroo R, Ahmad Y, Wang M, De Rossi S, Horsley T. Toward a definition of competency-based education in medicine: a systematic review of published definitions. Med Teach. 2010;32:631-7.

9. Accreditation Council for Graduate Medical Education. ACGME Outcome Project enhancing residency education through outcomes assessment: General Competencies. 1999. Available from: http://www.acgme.org/outcome/ comp/compFull.asp. Accessed November 9, 2014.

10. Joyce B. Introduction to Competency-based education. Facilitators guide ACGME. 2006. Available from: $h t t p: / /$ www.paeaonline.org/index.php .ht $=a /$ GetDocument Action/i/161740. Accessed December 27, 2014.

11. Weinberger SE, Pereira AG, Lobst WF, Mechaber AJ, Bronze MS, Alliance for Academic Internal Medicine Education Redesign Task Force II. Competency-based education and training in Internal Medicine. Ann Intern Med. 2010;153:751-6.

12. General Medical Council. Tomorrow’s Doctors: Education Outcomes and standards for undergraduate medical education. Available from: http://www.gmcuk.org/ Tomorrow_s_Doctors_0414.pdf_48905759.pdf. Accessed December 27, 2014.

13. Frank JR, Danoff D. The CanMEDS Initiative: implementing an outcomes-based framework of physician competencies. Med Teach. 2007;29:642-7.

14. ten Cate O, Scheele F. Competency-based Postgraduate training: Can we bridge the gap between theory and clinical practice. Acad Med. 2007;82:542-7.

15. Harden RM. Outcome-based education - The future is today. Med Teach. 2007;29:625-9.

16. Holmboe ES, Sherbino J, Long DM, Swing SR, Frank JR, for the International CBME Collaborators. The role of assessment in competency-based medical education. Med Teach. 2010;32:676-82.

17. van Mook WNKA, Bion J, van der Vleuten CPM, Schuwirth LWT. Integrating education, training and assessment: competency-based intensive care medicine training. Neth J Crit Care. 2011;15:192-8.

18. Boursikot K, Etheridge L, Zeryab S, Sturrock A, Ker J, Smee S, Sambandam E. Performance in assessment: Consensus statement and recommendations from the Ottawa conference. Med Teach. 2011;33:370-83.

19. Chacko TV. Moving towards competency-based education: Challenges and the way forward. Arch Med Heath Sci. 2014;2:247-53.

20. McGaghie WC, Miller GE, Sajid AW, Telder TV. Competency-based Curriculum Development in Medical Education. An Introduction. Geneva: World Health Organization; 1978.

21. Harden RM. Outcome-based education - the ostrich, the peacock and the beaver. Med Teach. 2007;29:666-71.

22. Smith SR, Dollase R. AMEE guide No. 14: Outcomebased education Part 2 - Planning, implementing and evaluating a competency-based curriculum. Med Teach. 
1999;21:15-22.

23. Dreyfus HL, Dreyfus SE. Mind over Machine: The Power of Human Intuition and Expertise in the Age of the Computer. Oxford: Basil Blackwell; 1986.

24. Batalden P, Leach D, Swing S, Dreyfus H, Dreyfus S. General competencies and accreditation in Graduate medical education. Health Affairs. 2002;21:103-11.

25. Nasca TJ, Philibert I, Brigham T, Flynn TC. The next GME accreditation system - rationale and benefits. New Eng $\mathrm{J}$ Med. 2012;366:1051-6.

26. van Loon KA, Driessen EW, Teunissen PW, Scheele F. Experiences with EPAs, potential benefits and pitfalls. Med Teach. 2014;36:698-702.

27. Singh T, Modi JN. Workplace based assessment: A step to promote competency based training. Indian Pediatr. 2013;50:553-9.

28. Tekian A, Hodges BD, Roberts TE, Schuwirth L, Norcini J. Assessing competencies using milestones along the way.
Med Teach. 2014;19:1-4.

29. Medical Council of India Regulations on Graduate Medical Education 1997. Available from: http://www.mciindia.org/ RulesandRegulations/GraduateMedicalEducation Regulations1997.aspx. Accessed November 10, 2014.

30. Medical Council of India. Vision 2015. Medical Council of India. New Delhi. 2011. Available from: http:// www.mciindia.org/tools/announcement/MCI_booklet.pdf. Accessed November 10, 2014.

31. Medical Council of India Regulations on Graduate Medical Education 2012. Available from: http://www.mciindia.org/ tools/announcement/Revised_GME_2012.pdf. Accessed October 2, 2014.

32. Medical Council of India, Post Graduate Medical Education Regulations 2000, Medical Council of India, New Delhi. Available from: http://www.mciindia.org/Rules-andRegulation/Postgraduate-Medical-EducationRegulations-2000.pdf. Accessed November 29, 2014. 